\title{
Childcare practices of Polish Migrants in the Netherlands: Comparison with the countries of origin and destination
}

\author{
Alžběta Bártová, Erasmus University Rotterdam, the Netherlands \\ Kasia Karpinska, Sociaal en Cultureel Planbureau, the Netherlands
}

\begin{abstract}
Both formal and informal types of child care are important sources of support for working parents and especially women. However, little is known about the way migrant families combine their work and family responsibilities in a context of an absent or limited social support network. We explore this issue using the example of Polish migrant parents living in the Netherlands and compare their practices to those of their Dutch and Polish counterparts in the Netherlands and Poland. The aim of our research is to investigate whether migrant parents adapt to the new institutional context, draw on the childcare norms of their home country, or whether they adopt a unique strategy that reflects their specific position of migrants, formulated as separate hypotheses. We found support for all of the three hypotheses and showed that the childcare practices of Polish parents living in the Netherlands are highly dependent on the age of the youngest child. We also found that the extent to which Polish migrants integrate into the Dutch society can be an important predictor of their childcare strategies when the children are very young.
\end{abstract}

Keywords: Polish migrants; childcare practices; childcare policies; country of origin; country of destination

\section{Introduction}

By settling in a new country, migrants experience a life-changing event that exposes them to a new institutional and cultural setting and limits their access to previously available social support (Wingens, Valk, Windzio, \& Aybek, 2011). The consequences of this transition for different life domains have been widely studied. In the migration literature, much attention has been paid to the integration of migrants in the host countries, to transnational families, provision of intergenerational care, and to the formation of new ties and support network in host countries (Da, 2003; Koelet, Van Mol, \& De Valk, 2017; Nijhoff, 2017; Piętka-Nykaza \& McGhee, 2017). However, little attention has been paid to how migrant parents balance work and family responsibilities on a daily basis. Migrant parents find 
themselves in a very specific situation. They are often deprived of the informal support network of family and friends and can face obstacles in pursuing the institutional support due to lack of knowledge or financial constraints. The situation might be even more complex for migrant parents who come from a country with traditional views of childcare practices and who move to a country with more progressive and gender egalitarian attitudes to childcare and female employment.

The potential difficulties particularly female migrants with small children can face are outlined in contemporary research. The evidence shows that mothers living in countries where traditional gender views dominate have weaker labour market attachment compared to mothers who live in countries with dominating egalitarian views (Andringa, Nieuwenhuis, \& Van Gerven, 2015). Thus, there might be mismatches in the expectations of female migrants with small children and the expectations the majority population places on them. Breidahl and Larsen (2016) show, for example, that immigrants' attitudes towards women's paid work adapt at a high pace, but less strongly so for migrants from the countries of the former Soviet Union and from Southern Europe.

Studies that examine the childcare practices among immigrants frequently focus on the use of welfare state provisions. Scandinavian scholars have been predominantly concerned with the question of whether family migration and strong attachment to more traditional family models undermine the development towards a more egalitarian society (e.g. Eggeb $\varnothing, 2010$; Lister, 2009; Siim, 2007). In their recent qualitative study, Bjørnholt and Stefansen (2018), compared how Polish and Norwegian families adapt and cope within the normative dual earner/dual carer model that is prevalent in Norway, and found that Polish migrants used welfare state provisions to shape new and more gender equal family practices. Conversely, the available evidence on migrant populations in Australia and the United States suggests that migrant families tend to rely on parental and family-based care rather than institutional care (Da, 2003; Turney \& Kao, 2009). Recent studies also revealed that grandparents are an important source of childcare support for migrants despite the geographical distance between the family members. The evidence from qualitative studies shows that grandparents often step in and provide support with childcare for extended periods of time to help parents combine their work and family responsibilities during school holidays and times when childcare is less accessible (Bojarczuk \& Mühlau, 2017). However, they cannot offer more regular and readily available childcare support. Although those studies offer valuable insights into childcare strategies of migrant parents, their authors either focus exclusively on migrant populations, compare migrants with the native population in the host country or with the native population in the country of origin. We argue that to understand the choices migrant parents make, more elaborate models comparing the migrant populations with the native populations in the destination and the host countries is necessary.

Our paper, therefore, investigates how Polish migrant parents of small children adapt to the new context of life in the Netherlands. We do so by exploring the childcare strategies of Polish migrants in the Netherlands and compare them to the childcare patterns exhibited by parents in the countries of origin 
and destination. The Netherlands has become one of the primary destinations for Polish nationals following the accession of Poland to the European Union. The interest in the Netherlands as a destination country even strengthened after the labour market restrictions were abolished in 2007. Poland is characterised by a traditional gender ideology prescribing that childcare is mostly a female duty and should be organised within the family. The Dutch, on the contrary, tend to espouse more gender egalitarian attitudes and make more use of the formal childcare arrangements. Also, the institutional settings of these two countries differ greatly - while access to childcare facilities in Poland remains restricted, the formal childcare in the Netherlands is widely available (Mills et al., 2014). To our knowledge, no other study has compared childcare strategies of migrants with the majority populations both in the country of origin and destination using quantitative data. By examining the patterns of the three groups, we contribute to the migration literature by offering a detailed account of adaptation to the host society.

To answer the research question posed in this study, three data sets are used. We employ the Gender and Generations Surveys (GGS) for Poland, the Netherlands Kinship Panel Study (NKPS) for the Netherlands and complement them with the Families of Poles in the Netherlands (FPN) data (Karpinska, Dykstra, \& Fokkema, 2016). The FPN data were collected between October 2014 and April 2015 among recent registered Polish migrants aged 18-59. In all data sets, respondents reported on what childcare care arrangements a household applied. Only information on families with at least one child under the age of four was selected in the analyses. The restriction according to the child's age was introduced to ensure comparability between the samples. The age of four was selected because it is the age when children in the Netherlands usually enter primary school.

In the following sections, we will briefly introduce the different paths of the development in childcare policies in the Netherlands and Poland as well as a summary of the contemporary state of the childcare policies in the respective countries. Our hypotheses are outlined in a separate section, which is followed by a description of our data and samples and by interpretation of the results of our analyses and concludes with suggestions for future research.

\section{The development of childcare policies in Poland and the Netherlands}

The development of formal childcare services in Poland and the Netherlands has been radically different in the two countries. It has been largely shaped by the post-war economic development and the influence of religious groups in both countries (Heinen \& Wator, 2006; Henkens, Meijer, \& Siegers, 1993). Whilst in the Netherlands high unemployment and a smaller industrial sector did not require women to enter the labour market, in Poland the situation was quite the opposite (Berkel \& Graaf, 1998; Hartog \& Theeuwes, 1993). Women in Poland were encouraged to take part in rebuilding the country's economy destroyed by the war and they entered the labour market in large numbers shortly after the war to account for the shortage in the male workforce (Hajdo, 2006). 
The influx of female labour force in Poland went hand in hand with investments into childcare facilities that much increased the number of available spaces for pre-school children and also for children under the age of three. Later on, to deal with an increasing demand and the increasing pressure to improve the quality of the childcare facilities, the Polish government decided to invest in less costly solutions home-based childcare. In 1968, the Polish government introduced two-year-long unpaid childcare leave for mothers, which was further extended to three years in 1972 (Heinen \& Wator, 2006). Financial benefits for the childcare leave were introduced only in 1981 when the childcare leave was transformed into parental leave and made available under certain circumstances. To facilitate the work-family balance, in 1975 the Polish government introduced an early retirement option for women who provide child care for their grandchildren (Heinen \& Wator, 2006).

The collapse of the state socialism in 1989 brought a refamilialization trend to the family policy in Poland and other Central and Eastern European countries (Steven Saxonberg \& Sirovátka, 2006). The strengthened orientation towards home-based child care and gendered division of paid and unpaid work was fuelled by several factors amongst which the economic transformation played an important role. The transition from centrally planned economy to market economy also brought a rapidly increasing unemployment rates and long-term unemployment (Oyrzanowski \& Paleczny-Zapp, 1993). The transition disproportionately affected women, as they were more likely to become unemployed and experience long-term unemployment compare to men (I. E. Kotowska, 1995). Women also experienced great difficulties when trying to combine work and family responsibilities. Due to their unfavourable economic position, many mothers did not use their entitlements to parental leave and those who did experienced great difficulties when trying to return to the labour market (ibid.).

At the beginning of the 1990s the state support for families registered considerable retrenchment. Although the network of childcare services was generally smaller than in other Eastern European countries, it got even smaller after 1989. In 1985, only about 5\% of children under 3 and $50 \%$ of 3 to 6 years old attended childcare facilities (Szelewa, 2012). After 1989, the state cut its support for childcare facilities and transferred the financial responsibility to municipalities. At the same time, companies withdrew or significantly limited their support for childcare services provided to their employees. This resulted in drastic reduction in the numbers of crèches and kindgartens and increase in costs for parents, which projected itself to the decline in proportion of children attending these facilities (2\% of 0-3 and $38 \%$ of 3-5 year olds in 2004) (I. Kotowska, Jósźwiak, Matysiak, \& Baranowska, 2008). The maternity and parental leave remained largely unchanged in this period (16 weeks of fully paid maternity leave followed by three-year long parental leave with means-tested benefits). In 2006 the maternity leave was extended to 18 and after a series of further extensions up to 26 weeks in 2014 (Szelewa, 2017).

The strong political and societal position of the Church in Poland further contributed to the spread of childcare ideals that see the mother as the main care provider and as the best source of care and earlychild education (Szelewa, 2017). Childcare facilities for children under the age of three appear to carry 
their legacy from the era of state socialism and are regarded by many parents as of insufficient quality (Keryk, 2010; S Saxonberg \& Szelewa, 2007). The mother-centred childcare ideal reflected in the family policies is also supported by the general public as Poles tend to prefer traditional gender division of labour and women as the main carers (Edlund \& Öun, 2016). We can observe these preferences also in the evaluation of the statement that "Women should be prepared to cut down on paid work for sake of family" by the respondents of 2010 European Social Survey. In Poland, 52.8\% respondents between the age of 20 and 64 agreed with this statement with negligible gender differences in the responses. In contrast, about $24.2 \%$ of respondents in the Netherlands agreed with this statement (ESS Round 5: European Social Survey Round 5 Data, 2010). However, in recent years the parents' perception of formal childcare facilities has begun to change and the supply of childcare services, especially for children under the age of 3, considerably increased (from 571 in 2010 to 2,705 in 2015) (Szelewa, 2017).

Despite the relatively low support for the mother-centred childcare ideal in the Netherlands, not a long time ago these attitudes were dominant there as well. Until the 1990s, working mothers and children being cared for in institutions were considered by the general public as immoral practices (Bussemaker, 1998). The reason for such a difference between the Netherlands and Poland in the approach to childcare can perhaps be found in the post-war development that was radically different to Poland. The Netherlands experienced high unemployment following the end of the Second World War and the development in industry did not approximate the development in Poland. A female workforce, therefore, was not needed and at the same time when Polish women were entering the labour market, Dutch women were leaving upon marriage (Pott-Buter, 1993). The main role of a woman was to be the role of a mother and her main responsibility was to be found in the family.

Consequently, childcare facilities in the Netherlands were almost non-existent until the late 1970s and primarily targeted at single mothers and disadvantaged children (Bussemaker, 1998). The motivational factor behind state investments into childcare was not female employment, as it was in Poland in the 1950s, but the interest of children and their social development (ibid.). Nonetheless, apart from some private initiatives the supply of formal childcare did not improve until the beginning of the 1990s when the demand for female labour force increased in order to improve the international competitiveness of the Netherlands. The rhetoric regarding childcare facilities shifted towards the interests of female workers and gender equality. The development of contemporary childcare policies in the Netherlands has been built around so-called 'combination scenario' that divides the responsibilities for childcare between the state, employers and parents to ensure work-family balance and facilitate women's participation on the labour market (Knijn \& Saraceno, 2010). Since 2006, employers are obliged to contribute one-sixth of the childcare costs for each parent (ibid.). The state, on the other hand, contributes to the childcare through tax-deductible benefits that are dependent on the economic activity and income of both parents. 
Table 1. Childcare policies in Poland and the Netherlands (2011).

\begin{tabular}{|c|c|c|c|c|c|}
\hline Leave Policies & & Eligibility & Duration & Allowance & Flexibility \\
\hline \multirow[t]{2}{*}{ Maternity leave } & $\mathrm{NL}$ & $\begin{array}{l}\text { Insured employed and } \\
\text { self-employed }\end{array}$ & 16 weeks & 100\%, ceiling & $\begin{array}{c}4 \text { weeks must be taken } \\
\text { before, } 10 \text { weeks after } \\
\text { childbirth }\end{array}$ \\
\hline & $\mathrm{PL}$ & $\begin{array}{c}\text { Insured employed and } \\
\text { self-employed }\end{array}$ & 22 weeks & $\begin{array}{c}100 \% \text { average } \\
\text { earnings, no ceiling }\end{array}$ & $\begin{array}{c}2 \text { weeks must be taken } \\
\text { before, } 14 \text { weeks after } \\
\text { childbirth }\end{array}$ \\
\hline \multirow[t]{2}{*}{ Paternity leave } & $\mathrm{NL}$ & $\begin{array}{l}\text { Employed male and } \\
\text { female partners }\end{array}$ & 2 days & 100\%, no ceiling & $\begin{array}{c}\text { Taken within } 4 \text { weeks } \\
\text { after childbirth }\end{array}$ \\
\hline & $\mathrm{PL}$ & $\begin{array}{c}\text { Insured employed and } \\
\text { self-employed }\end{array}$ & 1 week & $\begin{array}{c}100 \% \text { average } \\
\text { earnings, no ceiling }\end{array}$ & $\begin{array}{l}\text { Taken within } 12 \\
\text { months after childbirth }\end{array}$ \\
\hline \multirow[t]{2}{*}{ Parental leave } & $\mathrm{NL}$ & $\begin{array}{l}\text { Employed for at least } \\
12 \text { months with the } \\
\text { same employer }\end{array}$ & $\begin{array}{l}\text { 26x usual working } \\
\text { hours (individual } \\
\text { entitlement }{ }^{1} \text { ) }\end{array}$ & $\begin{array}{l}\text { tax reduction; } \\
€ 712 / \text { month or } \\
€ 4.11 / \text { hour }\end{array}$ & $\begin{array}{l}\text { Recipients must work } \\
\text { part-time }\end{array}$ \\
\hline & $\mathrm{PL}$ & $\begin{array}{c}\text { Employed for at least } 6 \\
\text { months }\end{array}$ & $\begin{array}{c}36 \text { months (family } \\
\text { entitlement }{ }^{2} \text { ) }\end{array}$ & $\begin{array}{c}€ 100 / \text { month for } 24 \\
\text { months, means-tested }\end{array}$ & $\begin{array}{l}\text { Can be taken in one } \\
\text { block or } 4 \text { separate } \\
\text { blocks }\end{array}$ \\
\hline Childcare Services & & Age range & Opening hours ${ }^{3}$ & Price & \\
\hline Kinderopvang & $\mathrm{NL}$ & $0-4$ years & $7: 30-18: 30$ & $€ 7.16 /$ hour & \\
\hline Gastouder & $\mathrm{NL}$ & $0-13$ years & - & $€ 5.59-7.12$ /hour & \\
\hline Zlobek & $\mathrm{PL}$ & 20 weeks - 3 years & $6: 30-17: 30$ & $€ 50-350 /$ month 4 & \\
\hline Przedszkola & PL & 3-6 years & $6: 00-17: 00$ & $€ 0-500 /$ month $^{4}$ & \\
\hline \multirow[t]{3}{*}{ School } & & School age & $\begin{array}{c}\text { Compulsory school } \\
\text { age }\end{array}$ & & \\
\hline & $\mathrm{NL}$ & 4 & 6 & & \\
\hline & $\mathrm{PL}$ & 6 & 7 & & \\
\hline
\end{tabular}

Notes: ${ }^{1}$ Mother and father can each use this maximum amount of leave. The right cannot be transferred from one parent to another. ${ }^{2}$ Mother or father can use this leave. ${ }^{3}$ The opening hours here are only approximate. The exact opening hours vary across facilities but remain in close proximity of the opening hours presented in the table. ${ }^{4}$ The price varies across the facilities and also depending on whether the facility is public or private and the hours for which parents use them. For instance, public Przedszkola between 8:00 and 13:00 is free of charge. Parents using public Przedszkola have to pay extra fee for meals and any hours outside this 8:00 - 13:00 range. 
The conditions of working parents in the Netherlands were further improved by the introduction of parental leave in 2001. Although the leave was unpaid, state employees were entitled to $75 \%$ of their average earnings and some private employers introduced their own parental allowance schemes (Lewis, Knijn, \& Martin, 2008). In the same year, employees gained a right to request part-time or full-time employment from their employers (Booth \& van Ours, 2013). Concomitantly, the rights of part-time employment were equalised with the rights of full-time employment. This gave parents more freedom in the way they organise their work and family responsibilities. The series of reforms not only enabled mothers to remain in close touch with their work but also enabled fathers to assume more responsibilities for child care and childrearing. Consequently, the image of working mothers and caring fathers became more and more acceptable in Dutch society, which is also reflected by the relatively low support for the statement that "women should be prepared to cut down on paid work for sake of family" $(24.2 \%)$.

\section{Institutional settings for child care in Poland and the Netherlands}

Table 1. summarises the childcare policies in Poland and the Netherlands. The data refers to the years that correspond with the year of the secondary data collections (Generation and Gender Survey Poland, Netherlands Kinship Panel Study, Families of Poles in the Netherlands). The Polish Generation and Gender Survey (GGS-PL) data were collected in 2011. At that time, Poland provided their young families with maternity, paternity and parental leave. The maternity leave was available to all insured employees and self-employed mothers for 22 weeks. The maternity leave allowance compensated mothers for $100 \%$ of their average earnings. Employed fathers and insured self-employed fathers were able to use paternity leave that was one week long and compensated $100 \%$ of their average earnings. The parental leave is a family entitlement. The duration of parental leave was 36 months and the corresponding allowance was available to the eligible parents for up to 24 months. The benefits were flat-rate (about $€ 100 /$ month), means-tested and available mainly to the low-income families (I. E. Kotowska \& Michon, 2011).

The Netherlands Kinship Panel Study (NKPS) data were collected at the turn of 2010 and 2011. In 2011, the Netherlands also provided young families with maternity, paternity and parental leave. In contrast to Poland, the maternity leave was shorter (16 weeks) and the maternity allowance replaced $100 \%$ of women's previous earnings. The paternity leave was 2 days long and paid at $100 \%$ of fathers' earnings. The parental leave was based on an individual non-transferable right that reserved time for each parent and each child. Employed parents that were working for their employer for at least 12 months were entitled to parental leave that was calculated as a multiplicative (26) of their usual working hours. The parental leave was not associated with a financial benefit as such but with a tax reduction (Groenendijk \& Keuzenkamp, 2011). The eligibility conditions also did not allow the parents to completely interrupt their employment for the period of the parental leave and instead required them to 
keep working on a part-time basis. The data collection for the Families of Poles in the Netherlands (FPN) took place at the turn of 2014 and 2015. The maternity, paternity and parental leave policies in the Netherlands remained the same with the exception of the tax reduction for parental leave that was abolished in 2015 (den Dulk, 2015).

The structure of the pre-school childcare and the schooling system differ considerably between the two countries. Although the institutional childcare facilities for children under the age of 3 are similar, the coverage is dramatically different. For instance, in 2010 in Poland, only 3\% of children under three years of age were enrolled in a formal childcare facility. This was the lowest number among all EU countries for that year and an outcome that was way below the Barcelona target of 33\% coverage for this age category (Mills et al., 2014). In the same year, the Netherlands was among one of the topranked countries, with the coverage around 50\%. The contrast between the two countries in use of childcare facilities likely reflects the institutional and labour market differences. In the Netherlands, the condition that provided parental leave only if it was combined with part-time employment likely contributed to the increase in demand for childcare facilities and their flexibility. In contrast, in Poland the long parental leave and inflexibility of labour market might make it more difficult for parents to combine work and family life.

The funding of the childcare services in the two countries also likely contributed to the use of childcare facilities for small children. In the Netherlands, parents who use the daycare services and services of registered childminders are entitled to a childcare allowance (Kinderopvangtoeslag) that is calculated according to the parents' joint income, working hours, the number of hours a child spends in child care, and the number of own children in a childcare facility. Based on these criteria the childcare allowance covers between $33.3 \%$ and $95 \%$ of the childcare costs (Belastingdienst, 2017). The childcare allowance is also available to parents whose children are attending school but use after school care (Buitenschoolse opvang) and since 2018 the childcare allowance is also available to parents who use the services of the playgroups. The financial support of the parents encourages them to purchase childcare services, which in turn encourages the market to respond to such demand. In Poland, on the other hand, the support is oriented on the supply side and the responsibilities for childcare facilities lie predominantly with the municipalities. Although they exist, there is limited encouragement for privately provided childcare.

The differences between Poland and the Netherlands do not lie only in the number of childcare facilities available to parents but also in the different forms of formal childcare the two countries provide. Dutch parents of very young children have several choices when looking for childcare: daycare (Kinderopvang, available for children from birth until the age of 4); 'guest parents' (Gastouders, flexible childminders whose services are designed for children between the age of 0 and 13); or playgroup (Peuterspeelzaal, for children between the age of 2 and 3, provide child care for only a few hours per week). In Poland, the childcare facilities for pre-school children are divided into two main types of institutions. There are nurseries (Żłobki) for children from 20 months to 3 years old and 
kindergartens for children between the age of 3 and 6 (Przedszkoly). The children are entering the kindergartens in much higher numbers than the care facilities for children below three years old (in $201144 \%$ and $3 \%$ respectively). However, due to the limited number of spaces, it is not unusual that parents often end up on a waiting list before they can place their child in a kindergarten. The lack of spaces in the kindergartens is mainly caused by the transition from pre-school child care to school because the beginning of school is concentrated in September. The concentrated transition period from pre-school care to school causes a bottleneck situation where parents need to wait for this one period in a year when the spaces in kindergartens free up. The transition is much smoother in the Netherlands where the children usually start attending the preparatory classes the day after their fourth birthday.

The differences between Poland and the Netherlands are also in the intensity of the use of childcare services. Whilst the majority of Dutch children are cared for on a part-time basis (less than 30 hours a week), in Poland the care is mostly used on a full-time basis and it is the case also for children under the age of three. This clear divide in part-time and full-time childcare usage links with the structure of the labour market and female employment patterns observed in both countries. Whereas part-time positions in Poland remain scarce - approximately $10 \%$ of all available positions are part-time (Matysiak, 2009), in the Netherlands part-time employment is easily accessible. This structure of the labour market and scarcity of care facilities have consequences for female labour market participation Polish mothers either remain employed full-time, or they exit the labour market to fulfil caring responsibilities, whereas Dutch mothers stay employed but often work fewer hours. As noted by Saraceno (2011), in countries with lower coverage mothers have fewer options and "exclusive family/mother care is normative not because of explicit incentives, but because of a lack of publicly financed alternatives" $(2011,82)$. Consequently, the only option available for many working parents in Poland is reliance on family care, mostly by grandparents, or exit from the workforce.

In this section we demonstrated the vast differences in the opportunities and obstacles parents of young children face when trying to combine their work and family life. We also highlighted the cultural differences Polish migrants can face when starting their family in the Netherlands and the difficulties they may encounter when deciding on the right childcare strategy for their children. In the following section, we outline our hypotheses regarding the childcare strategy of Polish migrants in the Netherlands.

\section{Hypotheses about childcare strategies of Polish migrants}

Migration as a life-changing event can expose migrants to new patterns of behaviours and also, to different institutional arrangements. For migrants, the exposure to new life styles and institutional support also imply that the country of the settlement could have a substantial influence on how their life courses evolve after migration. However, as pointed out by Wingens et al. (2011), a different mechanism can apply. For instance, being exposed to a different culture and practices may accentuate 
the values, attitudes or cultural codes from the home country, leading to a stronger attachment to those values.

As outlined earlier, the differences in childcare policies and childcare ideals between Poland and the Netherlands are substantial. Although the family-based care is strong in both countries, in Poland, parents are more critical towards institutional care for very young children and the family policy supports gendered distribution of care responsibilities between partners. Polish parents also heavily rely on the help of the grandparents who are an important source of work-family balance. On the other hand, the Dutch are more accepting of women's and men's dual roles and the Dutch family policy actively promotes parents' freedom of choice with respect to child care and organisation of work and family life. At the same time, the state support is reserved only for dual-earner families. The Polish parents living in the Netherlands are therefore likely to face difficulties when combining their childcare ideals and societal expectations they are familiar with from their home country and those they are experiencing in the host country. Their difficulties may be further amplified because many migrants live at great distances from family members and cannot fully rely on the grandparental childcare and other advantages available to their counterparts in Poland.

We assume that Polish parents living in the Netherlands opt for one of three scenarios. According to our first hypothesis, the Polish migrants follow the familiar path of their Polish counterparts and reject the institutional care for very young children that are common in the Netherlands. In this paper, we understand institutional childcare to be a paid form of care for young children that is provided by a registered carer and subjected to regulations and quality control. The heritage hypothesis, as we call it, argues that Polish migrant parents are more likely to rely on sole parental care than Dutch parents and that they do not differ from Polish parents living in Poland. We expect this difference to be present across all child ages. According to our second hypothesis, the Polish migrants are influenced by the institutional context they live in and adjust their childcare strategies accordingly. The integration hypothesis argues that Polish migrant parents are more likely to rely on institutional-based child care compared to Polish parents living in Poland and that they do not differ from Dutch parents. Again, we expect that this persists across all the child ages.

In our third hypothesis, we take into consideration the specific situation of the migrants and their limited social support network mainly due to the absence of grandparents. The migration legacy hypothesis argues that Polish migrants in the Netherlands adopt childcare strategies that are distinct from their Dutch and Polish counterparts. The specificity of childcare strategies among Polish migrants may lie in the forms and types of childcare they use that may be distinct from those of native Polish and Dutch parents. Another demonstration of a distinct childcare pattern among Polish migrants may be the use of specific childcare strategies that differ from the native populations across the child age. Unfortunately, the data do not allow us to observe the differences in the childcare types between the samples. We will, therefore, focus only on the differences in the childcare strategies depending on the age of the youngest 
child. In the Netherlands, we expect that the use of institutional childcare is higher than in Poland from the very young ages due to the short maternity leave and flexible parental leave. In contrast, due to the long parental leave and the limited supply of formal childcare facilities in Poland, we expect the use of institutional child care to be low until the child reaches the age of two when we expect it to start rising. It is difficult to draw any expectations for childcare use across the child's age for the group of Polish migrants living in the Netherlands. They may follow the pathway of their counterparts in Poland, but the short maternity leave and flexible parental leave might increase the economic necessity for a second income. Also, the wide range of childcare options allows parents to select a childcare that best suits their preferences may encourage them to opt for an institutional child care earlier than Polish parents in Poland.

\section{Data and method}

This paper uses three sources of survey data - the first wave of the Families of Poles in the Netherlands (FPN) survey, the first wave of Generations and Gender Survey for Poland (GGS-PL) and the third wave of the Nederland Kinship Panel Study (NKPS). All three data sets are highly comparable, allowing for the comparison between Polish migrants in the Netherlands, Polish nationals in Poland and Dutch nationals in the Netherlands. The data for the Families of Poles in the Netherlands (FPN) survey was collected between October 2014 and April 2015 among Polish migrants aged 18-59, who registered in the municipality where they were living in the Netherlands after the EU enlargement in 2004. The sample was drawn from the population registers using simple random sampling, offering national coverage. Web and computer-assisted personal interviews were conducted among a total of 1,131 respondents. Both Polish and Dutch versions of the questionnaire were offered. The response rate for the first wave is $51 \%$ and is one of the highest among surveys of Polish migrants in the Netherlands (Karpinska et al., 2016). The blueprint for the FPN survey was the 2015 questionnaire of the Gender and Generations Survey (GGS, Aassve et al., 2015).

For Polish nationals, we use information from the GGS-PL. The data collection was part of the GGS project and was carried out in 2011. The sample was drawn from the population registers using multistage random sampling. In this survey, 20,000 Polish citizens aged 18-79 were questioned during Paper and Pencil interviews (PAPI). The first wave of the Netherlands Kinship Panel Study (NKPS) was collected between 2002 and 2005. It consisted of 8,161 main respondents aged 18-79. The third wave, that we use in our analysis, was conducted between April 2010 and February 2011. The interviews with the main respondents were conducted through Computer Assisted Personal, Telephone and Web Interviewing (CAPI, CATI, CAWI respectively). The total sample in wave 3 is 4,390 .

We selected our sample from individuals who declared they live with their partner (formal and informal relationships) and have at least one child younger than four that is also a household member. Our decision for selection of this age category was motivated by the institutional differences in childcare 
between Poland and the Netherlands. The most significant difference between the two countries is in the school age. In practice, about $95 \%$ of Dutch children start attending primary school when they turn four, which makes the age groups from four to six-year-olds (pre-school age for Polish children) between the two countries incomparable. We further restricted our sample by age of the respondents to match the age range in FPN. We, therefore, excluded all respondents who were more than 59 years old from NKPS and GGS-PL. The total size of our sample is 2,292 respondents. The subsample of Polish migrants living in the Netherlands (FPN) is $\mathrm{N}=256, \mathrm{~N}=1,756$ for the subsample of Polish nationals living in Poland (GGS-PL), and N=280 for the subsample of Dutch nationals living in the Netherlands (NKPS). In the study, we apply a couple perspective, where the information on both partners is used in the analysis. The information on partner's characteristics is collected from the respondent in FPN and GGS-PL, while NKPS applies a multi-actor design, where both the respondents and their partners participate in the survey.

\section{Dependent Variables}

To test our research hypotheses, we selected two dependent variables. Our heritage hypothesis is tested using a dichotomous variable that differentiates parents who are the sole carers of their child/ren (coded as 1) and parents that use some form of childcare either formal or informal. This variable was derived from the variables and categories that asked about any help with childcare received by the parents. The parents were coded as solely reliant on parental care if they did not report to use of any form of external help with childcare. The integration hypothesis is tested using a dichotomous variable that distinguishes parents who use some form of institutional childcare (coded as 1) from those who do not. The questions regarding the institutional child care vary across the datasets. Both GGS-PL and FPN specify different types of institutional child care facilities, such as day care centre, nursery or pre-school, self-organised childcare group or other forms of institutional arrangements'. The NKPS uses a broad category of institutional child care and does not specify the type of institutional child care facilities². To ensure comparability, we merged all the forms of institutional childcare from GGS and FPN into one category. Our migration legacy hypothesis is more general than the first two hypotheses and does not detail any specific strategy regarding childcare amongst Polish migrants living in the Netherlands. It argues that the childcare pattern is distinct from both Polish and Dutch nationals. Therefore, we did not select any

\footnotetext{
' In FPN, we constructed the institutional childcare variable out of six questions asking: "Got help from childcare from day care centre/nursery or pre-school/before-school-hours care centre/after-school-hours care centre/self-organised childcare group/other institutional arrangement?" In GGS-PL, we used three variables asking about "alternatives in childcare" that distinguish several categories of childcare. For the construction of the institutional childcare variable we used categories "day care centre", "nursery or pre-school", "after-school care centre", "self-organised childcare group", "other institutional arrangement".

The NKPS asks whether parents use paid child care. This question is followed by a set of questions asking about the type of paid childcare they use. The categories include family members, neighbours, private persons and institution but does not distinguish different types of institutional childcare similar to NKPS and FPN. We selected the category "institution" to construct our institutional childcare variable.
} 
specific dependent variable to test this hypothesis. Instead, the findings from the models testing the heritage and integration hypotheses were used to provide an answer to this argument.

Table 2. Descriptive statistics of the sample - mean values.

\begin{tabular}{|c|c|c|c|}
\hline & Dutch nationals & Polish nationals & $\begin{array}{l}\text { Polish migrants in } \\
\text { the Netherlands }\end{array}$ \\
\hline \multicolumn{4}{|l|}{ Childcare strategies } \\
\hline Parents only & $6.1 \%$ & $36.0 \%$ & $29.7 \%$ \\
\hline Institutional childcare & $63.9 \%$ & $29.8 \%$ & $41.0 \%$ \\
\hline Woman's age & 35.0 & 30.8 & 31.1 \\
\hline Man's age & 37.2 & 33.4 & 33.7 \\
\hline Age of the youngest child & 1.6 & 1.4 & 1.2 \\
\hline Number of children in the household & 2.2 & 1.8 & 1.4 \\
\hline \multicolumn{4}{|l|}{ Woman's educational attainment } \\
\hline Low & $8.6 \%$ & $5.8 \%$ & $15.2 \%$ \\
\hline Middle & $66.8 \%$ & $51.2 \%$ & $52.7 \%$ \\
\hline High & $24.6 \%$ & $42.2 \%$ & $32.0 \%$ \\
\hline \multicolumn{4}{|l|}{ Man's educational attainment } \\
\hline Low & $12.1 \%$ & $5.6 \%$ & $35.2 \%$ \\
\hline Middle & $67.9 \%$ & $64.1 \%$ & $46.1 \%$ \\
\hline High & $20.0 \%$ & $30.0 \%$ & $18.8 \%$ \\
\hline Woman is working & $86.8 \%$ & $46.8 \%$ & $48.0 \%$ \\
\hline Man is working & $97.5 \%$ & $92.7 \%$ & $93.8 \%$ \\
\hline $\mathbf{N}$ & 280 & 1,756 & 256 \\
\hline
\end{tabular}

\section{Explanatory and Control Variables}

We evaluate how parents of young children balance childcare and work responsibilities and how the practices differ across the three groups of Polish migrants in the Netherlands, Polish and Dutch 
nationals. Our main explanatory variables are therefore the three groups distinguished by the three different datasets we use in our analysis. To do so, we created three dummy variables for each of the dataset. However, since the institutional differences in the support for public childcare differ considerably between Poland and the Netherlands we expect that childcare practices may not only differ between the two countries but also by the age of the child. The indicator of child's age will, therefore, serve as our main indicator for testing the migration legacy hypothesis.

We control for various socio-demographic characteristics of the respondents and their partners such as their respective ages, educational attainment and economic activity. We control for educational attainment because the use of formal childcare is stratified, with highly educated mothers being the most likely users of this type of child care compared to their counterparts with lower educational attainment (Cloïn, Keuzenkamp, \& Plantenga, 2011; Krapf, 2014; Mamolo et al., 2011). The variable used in the analysis is the highest educational degree obtained, coded in International Standard Classification of Education (ISCED-97). First, we made a distinction between three levels of education: low (pre-primary education, primary education or first stage of basic education, and lower secondary or second stage of basic education, educational levels of ISCED 0,1 or 2), intermediate (upper secondary education, and post-secondary non-tertiary educations, education; ISCED 3 or 4) and high (first and second stage of tertiary education; ISCED 5 or higher). Due to the small sample sizes in some of the categories of partners' educational profile, we decided to set apart the respondent's and their partner's educational categories and distinguish between the educational attainment of women and men separately. Information on the labour market position of both partners was also included in the analysis because the economic activity is directly associated with the use of an external form of childcare. We opted for a simple distinction between working and not working individuals. Due to the low sample sizes in some of the categories in some of the datasets, we decided to differentiate between the employment of women and men separately instead of following the couples' employment profiles. Due to a large number of missing values on income in FPN, we had to exclude this indicator from our analysis. We also included child characteristics it the analysis: age of the youngest child and number of children in the household.

To test our hypotheses, we constructed two statistical models and executed the analysis in two steps. First, we applied logistic regression analysis to examine the determinants of the childcare strategies and potential differences between Polish migrants and the Polish and Dutch native populations. The first analytical model investigates the likelihood that parents are the sole carers for their children. The second model analyses the likelihood that parents use some form of institutional childcare. Second, to facilitate the interpretation, we estimated marginal effects, which give the change in probability by one unit of the predictor, when other variables are kept constant at sample means. 


\section{Results}

Table 2. provides information on the two types of childcare arrangements and sample demographics. Incidences of sole parental childcare for children under the age of four are similar for migrants and the Polish nationals - roughly one in three couples use neither formal nor informal childcare and perform all care tasks themselves. Only $6.1 \%$ of Dutch parents apply this strategy. The differences are also substantial in the use of formal childcare arrangements. About $63.9 \%$ of Dutch parents use formal childcare facility for their small children. The incidence is the lowest in Poland where only about $30 \%$ of parents use this form of childcare. This strategy is more common for Polish migrants living in the Netherlands who opted for formal childcare in $41 \%$ of cases. When we look at the differences between the sole parental care and the institutional childcare, we see that about third of each sample use some form of external childcare for their children but not institutional childcare (e.g., grandparents, other family members or friends).

The mean age of the female partners ranged from 30.8 for Poles, 31.1 years in the migrant's sample to 35 years for the Dutch. The mean age of the male partners is 33.7 years for migrants and 33.4 Poles in Poland, whereas the Dutch male partners were the oldest, and on average 37 years old. The samples varied concerning their educational attainment. The highest proportion of highly educated respondents and partners can be found in Poland where about $42 \%$ of women and $30 \%$ of men fall into this category. The lowest educational attainment can be found amongst the Polish migrants living in the Netherlands both for women (15.2\%) and men (35.2\%). However, in all the samples the middle level of educational attainment dominates. The differences in employment amongst fathers of at least one child under the age of four are negligible across the samples and exceeding $90 \%$ in all cases. The situation is radically different for mothers of young children. Whilst in the Netherlands about $87 \%$ of mothers work, this is the case for only $46.8 \%$ of mothers in Poland and $48 \%$ of Polish migrant mothers living in the Netherlands.

\section{Heritage hypothesis}

To test our hypotheses about the childcare practices of Polish migrants in the Netherlands we conducted logistic regression analysis using two dependent variables - the use of sole parental care and the use of institutional childcare. In the first analytical model, we test our heritage hypothesis, which argues that Polish migrant parents follow the behavioural patterns they are familiar with from their country of origin. We expect that the patterns will be similar due to socialisation processes but also due to a peer and family pressure. Although they live in a different country, migrants are rarely completely isolated from their family and friends who stayed behind (Share, Williams, \& Kerrins, 2017; Sime \& PietkaNykaza, 2015). The social and cultural influence from the home country may therefore still be strong. However, in our study, we do not focus on the exact trajectories of the influence from the country of origin to the migrants. The survey data we use in this analysis were designed with different purpose and 
therefore do not provide the opportunity to conduct such research. Instead, we focus only on the similarities in the childcare practices between the Polish migrants living in the Netherlands and Poles living in Poland. We use the age of the youngest child as a way to observe any deviations from the expected pattern of childcare use between the samples.

Figure 1. Predicted marginal probabilities of the interaction between the age of the youngest child and the three samples with 95\% confidence intervals (Model 1 - sole parental care).

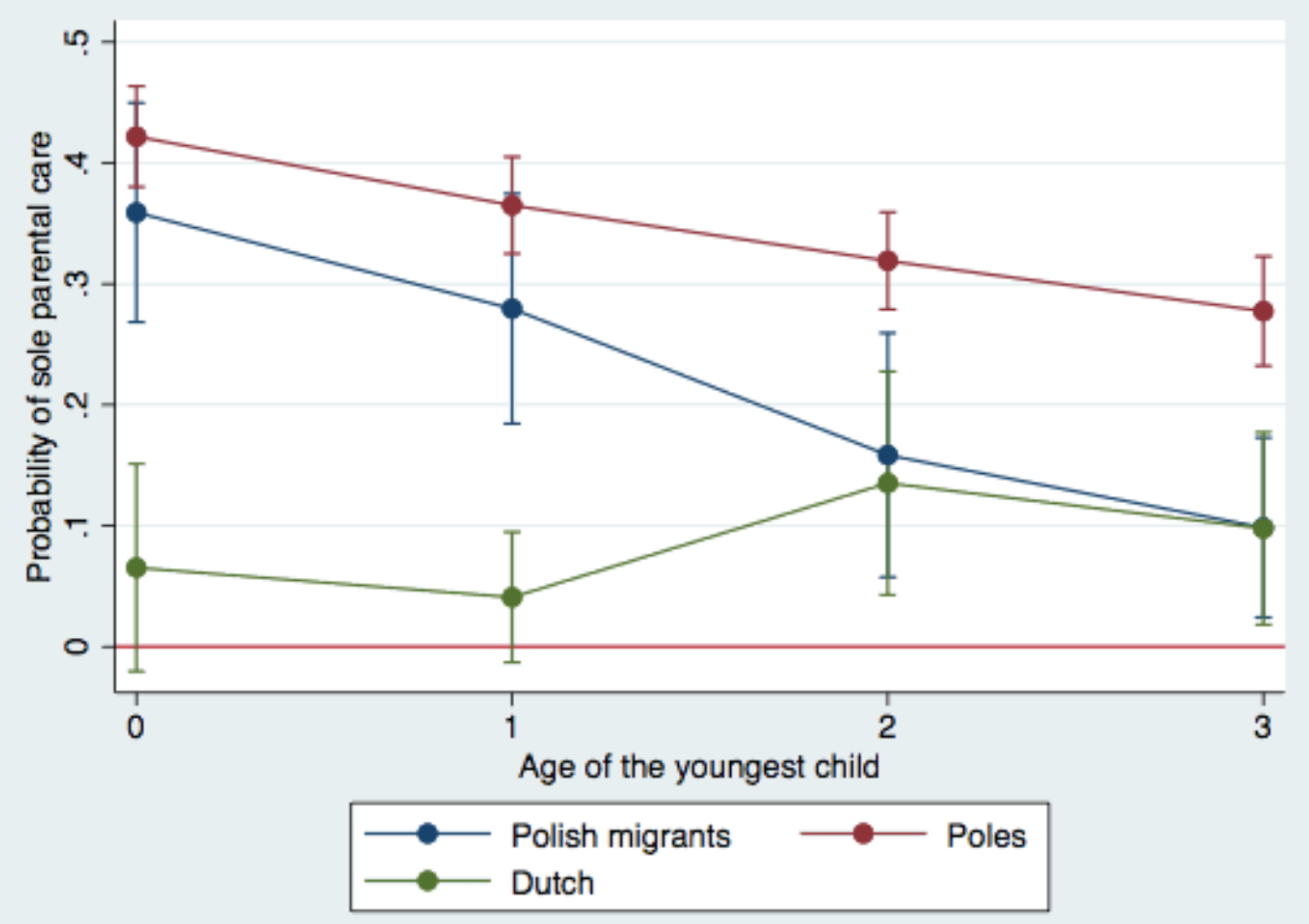

Source: FPN Wave 1, GGS -PL Wave 1, NKPS Wave 3.

Figure 1. plots the predicted marginal probabilities for the interaction effects between the three datasets and the age of the youngest child on the use of sole parental care (the full model can be found in the Appendix). It shows that Polish parents in Poland are most likely to rely only on themselves when ensuring care for their small children. Although the probabilities of using sole parental care decline with increasing age of children in Poland, it remains the highest amongst the three groups across all the age groups. When comparing the childcare practices of Poles with their Polish counterparts living in the Netherlands, we see that the pattern is similar for the youngest age groups $(<2)$. Although the migrants have a lower probability of solely relying on parental care, the difference in the predicted probabilities between the migrants and Poles in Poland are not statistically significant. However, from the age of two, the trajectories of these two groups start to diverge. Whilst in Poland the reliance on 
sole parental care remains high, it declines for the Polish parents in the Netherlands and converges with the Dutch parents by the age of three.

In contrast, parents in the Netherlands rarely rely only on themselves when ensuring care for their small children. The predicted probabilities of using sole parental care for children under the age of two are below 0.1. Although it increases in the older age categories, it remains low in general and close to the $10 \%$ probability. Our data shows that Dutch parents of two-year-old children are slightly more likely to use sole parental care than Dutch parents of any other ages. The probability then decreases again for the three-year-old children. There do not seem to be any structural differences that could account for this observation and we are inclined to ascribe it to the relatively small sample size of the Dutch sample. The results show that the Polish migrants tend to follow the childcare practice they know from Poland. However, this seems to be the case only for the very small children who are less than two years old. When the youngest child reaches the age of two, the Polish parents in the Netherlands seem to seek external childcare more often than their counterparts in Poland. From that point, their preferences for sole parental childcare seem to resemble those of the Dutch parents. These findings provide some support for the heritage hypothesis, but they also reveal that the childcare strategies are highly dependent on the age of the youngest child.

\section{Integration hypothesis}

The second analytical model tests the integration hypothesis which argues that the families of Polish migrants are open to the opportunities offered by the institutional childcare in the Netherlands and follow the childcare pattern of Dutch nationals. Figure 2. plots the predicted marginal probabilities for the interaction effects between the three groups and the age of the youngest child on the use of institutional childcare. It shows that in the Netherlands the use of formal childcare facilities is high (between 55\% and 60\% probability) and stable across the age groups. This corresponds with our expectations as the maternity leave is relatively short in the Netherlands and parental leave for the years covering by the survey was offered only on a part-time basis. In Poland, the use of formal childcare facilities is also relatively stable across the age groups but increases sharply when the youngest child reaches the age of three. In contrast to the Netherlands, in Poland, the use of formal childcare facilities is very low with predicted probabilities of about $20 \%$. This is also in line with our expectations as the parental leave in Poland expires when a child reaches the age of three and childcare facilities for younger children are scarce.

The difference in predicted probabilities for use of formal childcare is statistically significant for Dutch and Poles in Poland until the youngest child reaches the age of three when their values converge and the difference becomes statistically insignificant. Dutch parents are therefore much more likely to use institutional childcare with their small children than Polish parents in Poland. The situation is quite different for Polish migrants. They have a low predicted probability of using formal childcare for the 
youngest age category $(33 \%)$ but the predicted probabilities increase when the youngest child reaches the age of one and continues rising until the child is three years old. The outcomes show that for the youngest age category, there are no statistically significant differences in the preference for institutional childcare between the migrants and Poles in Poland. However, no statistically significant difference was also found between the migrants and the Dutch parents in the same category of child's age. This finding suggests that there might be parents amongst the Polish migrants who differ in their childcare strategy for the youngest children with some opting for institutional childcare and others opting for other than institutional forms of childcare.

Figure 2. Predicted marginal probabilities of the interaction between the age of the youngest child and the three samples with 95\% confidence intervals (Model 2 - institutional childcare).

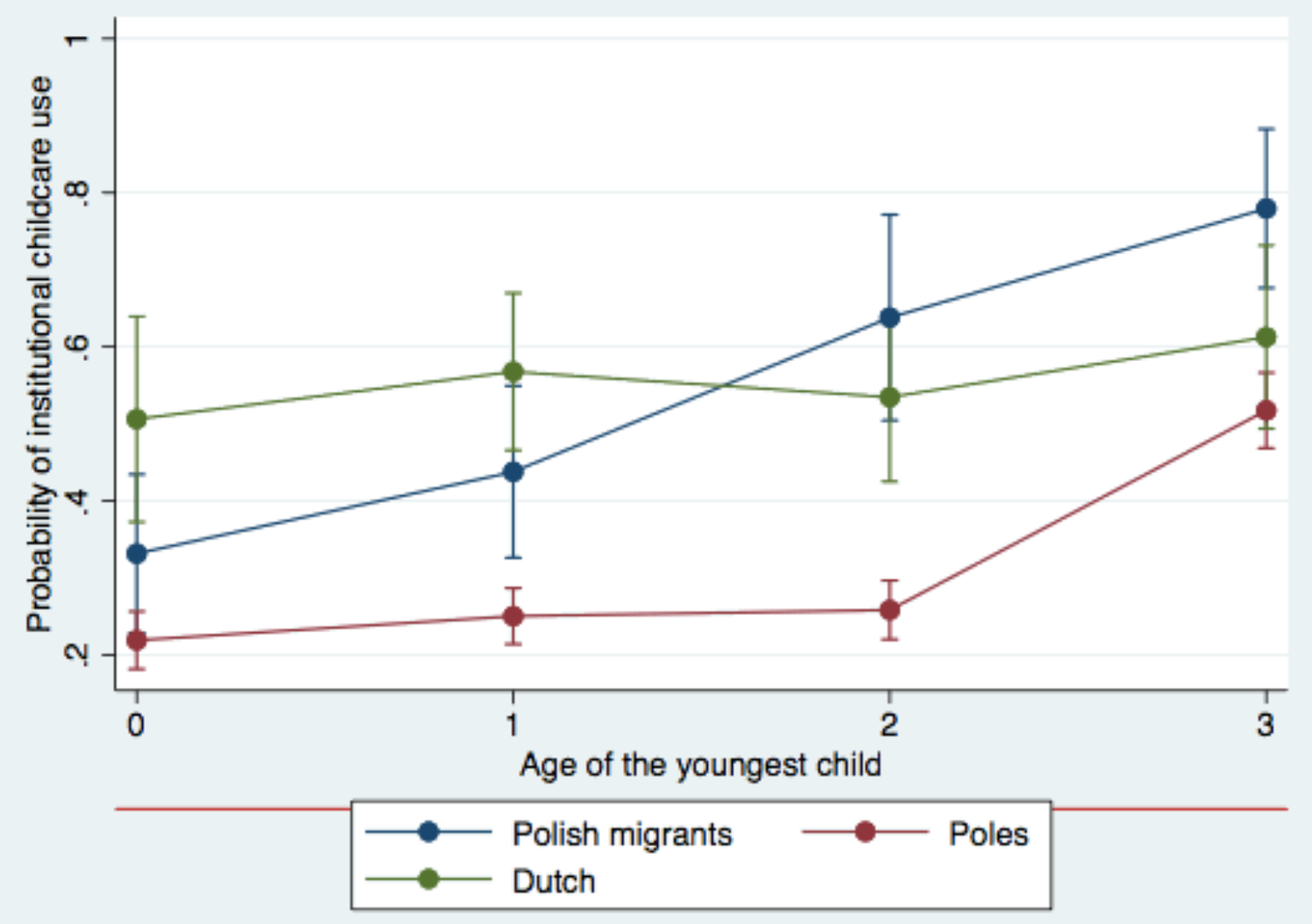

Source: FPN Wave 1, GGS -PL Wave 1, NKPS Wave 3.

The preferences for institutional childcare among Polish migrants become clearer in the older age categories. The difference in use of institutional childcare between Polish parents in the Netherlands and in Poland start to increase when the youngest child becomes one year old and continue rising. At the age of two, their predicted probabilities become higher than those of Dutch parents. This finding suggests that the use of institutional childcare is even more prevalent amongst Polish migrants than Dutch nationals. However, the differences between Dutch and Polish parents in the Netherlands are not 
statistically significant. Nonetheless, the results of the second analytical model revealed clear preference of Polish migrants for institutional childcare and with the exception of the youngest age category a clear diversion from the childcare practices in Poland. The high preference for institutional childcare may reflect the absence of readily available grandparental care for Polish migrants and the greater variation in the institutionalised childcare in the Netherlands than in Poland. The alternative forms of childcare (e.g., Gastouders) offer services that are provided in more home-like environment with smaller groups of children than in nurseries and pre-school childcare. At the same time, they also offer a great flexibility that mirrors the availability of part-time employment. These characteristics of the Dutch labour market, institutional childcare and part-time conditionality of parental leave may serve as motivational factors for migrant parents to place their children in institutionalised childcare earlier than parents in Poland. Although, the results provide some support for the integration hypothesis they again showed that the childcare practices of Polish migrants in the Netherlands are dependent on the age of the youngest child.

The two analytical models provided us with some support for the two hypotheses but also revealed patterns that make us cautious about fully accepting them. For instance, we did not find a clear preference for institutional childcare amongst the Polish migrants for the youngest age category. There are two possible explanations for the absence of an effect. On one hand, the outcome may be influenced by the presence of an older sibling. This means that the parents may use institutional childcare but with the older child rather than their youngest child. In other words, this age category may combine parents of one child who provide sole parental childcare and parents with at least two children who may use institutional childcare with their older child. Another explanation can be that there are indeed parents that differ in their preferences of childcare for their very small children - some opt for the sole parental care whilst others opt for institutional childcare. Another point for caution is the steep increase in the use of formal childcare facilities amongst Polish migrants. Compare to Dutch parents whose predicted probabilities fluctuate around 50\% across the age groups, Polish migrants experience an increase from about $33 \%$ at the age category from birth to one year of age to about $78 \%$ at the age of three. This could indeed reflect the unique situation of migrant parents who lack the social support network available to the native populations.

The two analytical models also reveal one outcome that we have not yet discussed. The first model showed that the Polish migrants with a one-year-old child are statistically more likely to rely on sole parental care than their Dutch counterparts. In the second model, however, the Polish migrants also appeared to be statistically more likely to use institutional childcare compared to their counterparts in Poland for the same age category. This points to some differences in the childcare preferences amongst Polish migrants and suggests that the age of one might be a critical moment regarding childcare on which migrant parents cannot agree. We, therefore, decided to further analyse this finding. 


\section{Migration Legacy Hypothesis}

The first two analytical models showed that the Polish parents in the Netherlands do not fully follow the childcare patterns of their counterparts either in the Netherlands nor in Poland. Instead, they seem to combine the best of both worlds. We found a relatively strong preference for home-based parental care for very young children but also a strong preference for institutional childcare with children who are at least two years old. Although migrant parents seem to stay at home with their children longer than Dutch parents, they are also more likely to place their children in a formal childcare facility at a younger age than Polish parents in Poland. This shows a rather distinct pattern of childcare practices and provides some support for the migration legacy hypothesis. Apart from the general patterns, we also found an unclear preference for particular childcare strategy amongst parents of one-year-olds. We interpret the lack of clear preference for a specific type of childcare in this age group as a reflection of different preferences amongst the group of Polish migrants in the Netherlands and their different cultural orientations. We assume that migrants that are more oriented towards building their life in the Netherlands are those who are more accepting of institutional childcare for very young children compare to their peers who reflect on their lives in the Netherlands as a temporary status and who have a strong attachment to their home country. At the same time, we assume that migrant parents oriented towards Poland will be more likely to rely on sole parental care than the migrants that are more oriented towards the Netherlands. We decided to empirically test this idea in additional models that include only the Polish migrants in the Netherlands. These analytical models mirror the original models 1 and 2.

To distinguish Polish migrants with an orientation towards the Netherlands from those who are more oriented towards Poland, we used latent class analysis ${ }^{3}$. The following dummy variables were used: both partners are Polish (yes/no), respondent participated in a language course (yes/no), owns property in Poland (yes/no), and intends to settle in the Netherlands or intends to return to Poland in a short future. Additionally, we included a categorical variable that captured the main reason for migration (e.g., work, family or other reason). Two latent classes emerged from this analysis - orientation towards Poland (72\% of respondents) and orientation towards the Netherlands ( $28 \%$ of respondents). Respondents who were classified as oriented towards Poland have a high likelihood of having a Polish partner (0.99) and substantial likelihood to have migrated for work-related reasons (0.66). The probability to stay longer in the Netherlands and owning a property in Poland was moderate $(0.38$ and 0.29 , respectively). The likelihood of the Poland-oriented migrants to participate in the language course is substantial (0.53). On the contrary, migrants classified as oriented towards the Netherlands, have a low probability of both partners being Polish $(0.11)$, moderate probability to migrate for family-related reasons $(0.57)$ and a high probability of participating in the language course (0.81). The likelihood of having shorter intention to stay in the Netherlands and owning a property in Poland was low in this group ( 0.17 and 0.17 , respectively).

${ }^{3}$ Details available upon request. 
When we look at the distribution of the types between different categories, we observe a clear gender and educational gradient. The migrants that are oriented towards the Netherlands are predominantly women (90.6\% compare to $58.6 \%$ in the Poland-oriented group) and they are more likely to be highly educated (52.8\% compare to $21.1 \%$ in the Poland-oriented group).

Figure 3. Predicted marginal probabilities of the interaction between the age of the youngest child and the three samples amongst Polish migrants (Model 3 - sole parental care).

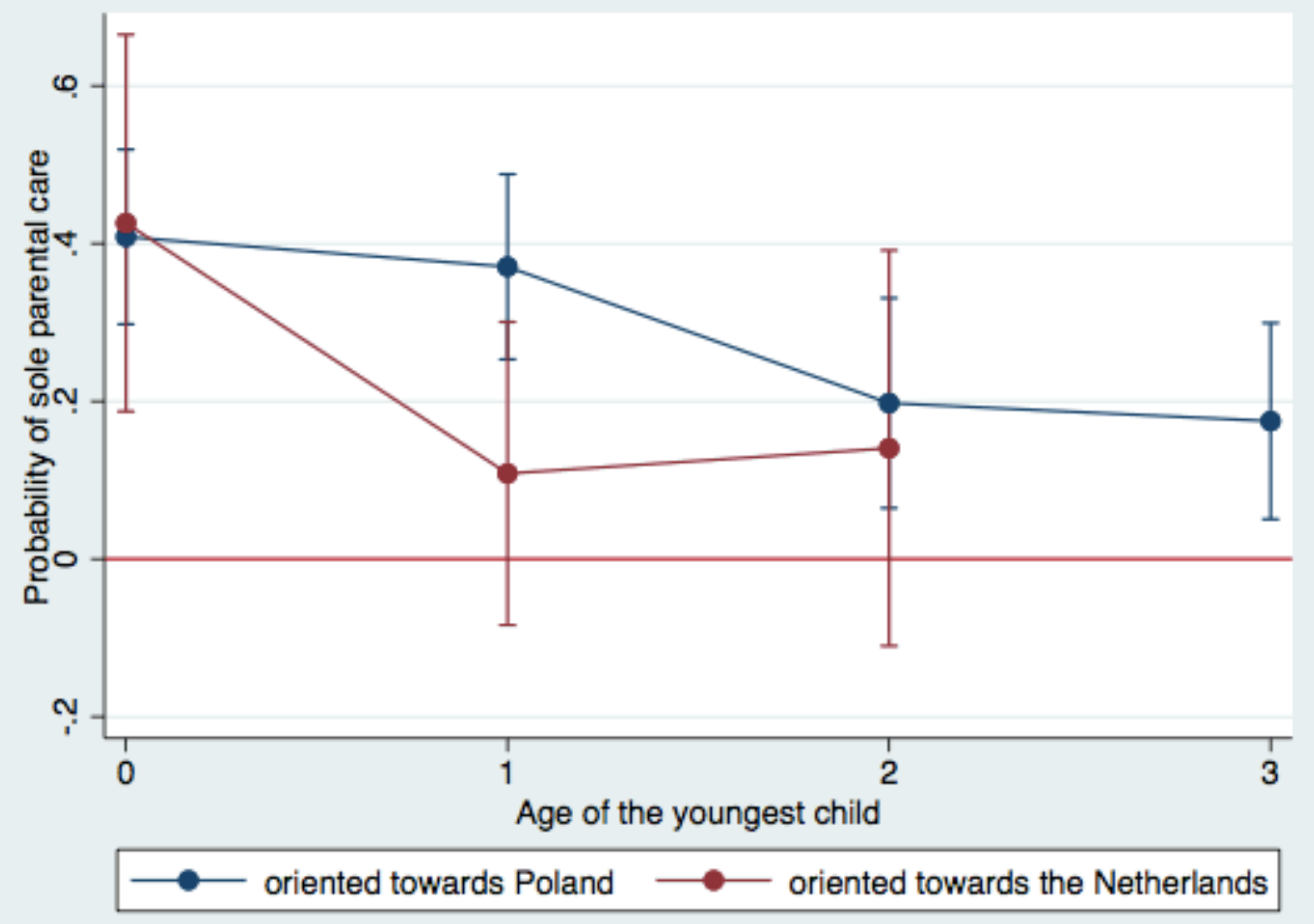

Source: FPN Wave 1

These classes were then used in the analysis predicting the use of sole parental and institutional care amongst Polish migrants by age of the youngest child. We run the analysis using analytical models 1 and 2 with only FPN data. Due to the small sample size of the FPN dataset $(\mathrm{N}=256)$ the analysis yields problems such as large standard errors and in one case perfect prediction of the outcome (Dutch oriented migrants with a three-year-old child). These results are, therefore, only modestly reliable and should be viewed with caution. We decided to present them here primarily to inform potential future research into this area when more suitable data become available. Figure 3. plots the interaction effect of age of the youngest child and migrants' orientation on sole parental care. Results reveal a strong consensus on the preference for sole parental care in the youngest age category between the groups of Dutch and Polishoriented parents. As outlined earlier, the largest difference in the preference for sole parental care can 
be found amongst parents with one-year-old children. Migrant parents with children in this age category who are oriented towards their home country are more likely to rely on sole parental care compared to their counterparts who are oriented towards the Netherlands. The preferences for sole parental care decreases sharply for the Poland-oriented parents and converge with the Netherlands-oriented parents at the age of two. The category at the age of three for the Netherlands-oriented parents is empty because none of these parents relies solely on parental care.

Figure 4. Predicted marginal probabilities of the interaction between the age of the youngest child and the three samples amongst Polish migrants (Model 4 - institutional childcare).

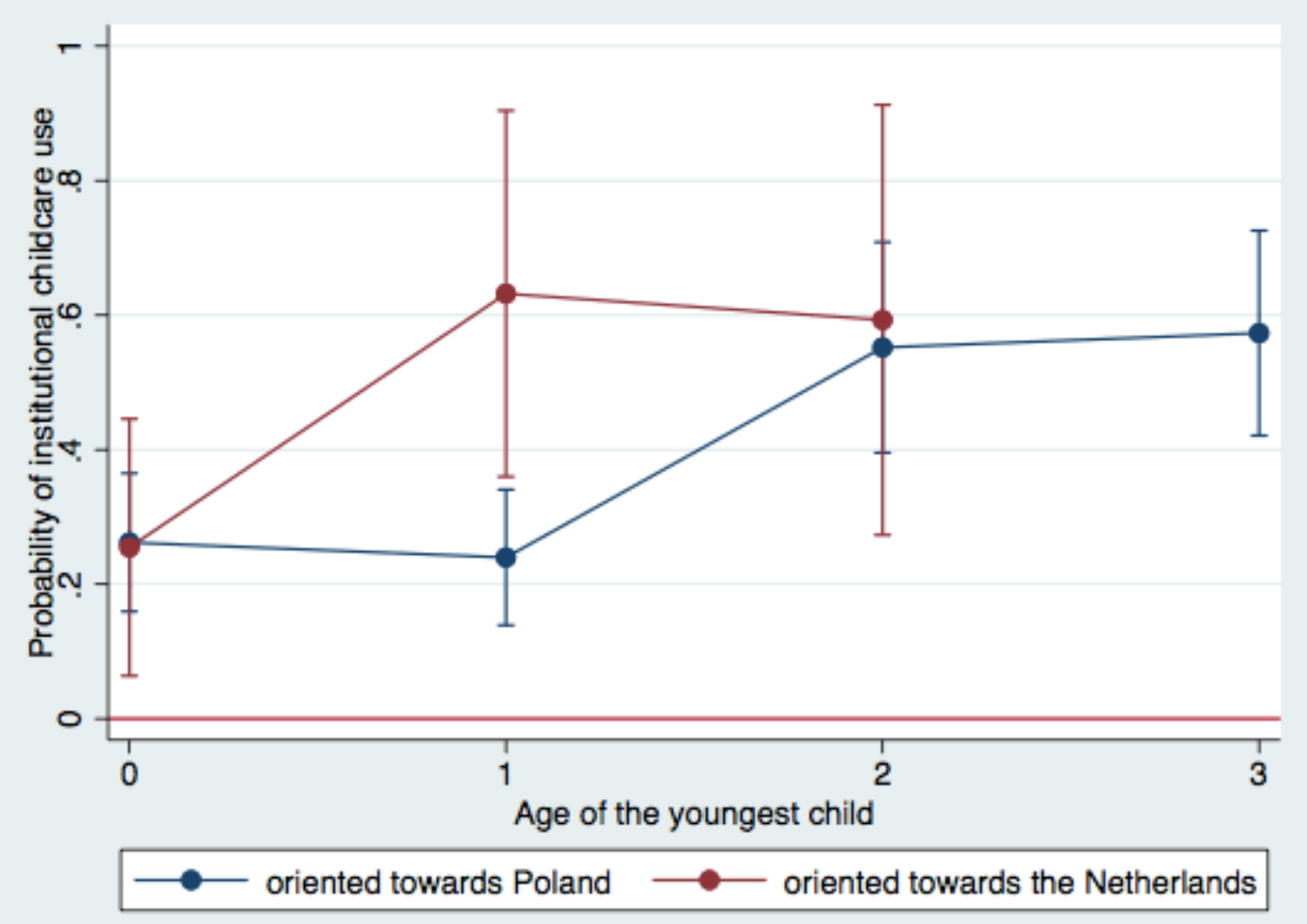

Source: FPN Wave 1

Figure 4. plots the interaction effect of age of the youngest child and the migrants' orientation on the use of institutional childcare. We found that there is no difference between both groups in the predicted probability of using institutional care in the youngest age category. Much as in the previous model, we found that the largest differences can be found amongst parents with one-year-old children. In this age category, migrants with a stronger orientation towards the Netherlands are more likely to make use of institutional child care, but this difference disappears after children turn two. The differences in the predicted probabilities are quite substantial with $63 \%$ for Polish migrants oriented towards the Netherlands and $24 \%$ for Polish migrants oriented towards Poland. Although the difference in the use 
of institutional child care between migrant parents of one-year-old children is statistically significant, this statistical significance disappears after controlling for the number of years the respondents spent in the Netherlands. Nevertheless, the differences remain substantial. The outcomes of this analysis suggest that in controversial issues, such as the ideal age at which a child might start being cared for by someone else than their parents, the context of the host country plays a more prominent role among parents who are prepared to integrate in their host country than among parents who maintain close bonds with their home country.

\section{Robustness checks}

Our analysis is based on a sample of parents with at least one child that is less than four years old. In total, 1,052 respondents in our sample had only one child at the time of the survey and the remaining 1,239 respondents had more than one child. Although our statistical models control for the number of children in the household, the relationship between the three samples and the use of sole parental care and institutional child care could be affected by the presence of an older child in the household. We, therefore, run robustness checks for our two models using only one-child families. This greatly affected our sample sizes across the datasets and the child's age. The total sample size of 1,052 families with one child consists of 789 respondents from the GGS-PL, 178 respondents from FPN and only 85 respondents from NKPS (this yielded 18 respondents with a child less than 1, 34 with one-year-olds, 20 and 13 with two- and three-year-olds respectively). Although the low sample sizes affected the significance levels, the patterns of the relationship between the samples, the childcare strategy and the age of the child remained very similar to those depicted in Figures 1. and 2.

\section{Conclusions}

In this paper, we investigated the childcare practices of Polish migrants in the Netherlands and compared them to those of Dutch and Polish nationals living in the Netherlands and Poland respectively. We outlined three possible strategies according to which the Polish migrants either follow the familiar patterns of their counterparts in Poland (heritage hypothesis), draw on the opportunities of the host country and follow the patterns of their counterparts in the Netherlands (integration hypothesis), or follow a unique path that reflects their specific situation of migrants with severed social support networks (migration legacy hypothesis). Our results revealed that the Polish migrants in the Netherlands maintain a strong affiliation with the childcare practices in Poland for the youngest children (less than one year old). In this category, we found a strong consensus amongst the Polish migrants and preference for sole parental care. However, the similarities between the migrant parents and their peers in Poland start to clearly divert when their youngest child reaches the age of two. From this age onwards, the Polish migrants start to follow the childcare practices of their counterparts in the Netherlands. Apart from that, the Polish migrants in the Netherlands shift from the strong support for sole parental care to the acceptance of institutional childcare at younger ages than it is common in Poland. This suggests a 
strong influence of the host country that facilitate the parents' acceptance of the institutional childcare for younger children than it is accepted in Poland. Although these findings provide some support for the first two hypotheses, they also show that the childcare strategies are highly dependent on the age of the youngest child and therefore that the Polish migrants in the Netherlands tend to follow a unique childcare pattern.

The cultural and social values of the home country seem to be particularly strong in controversial cases such as the question of the ideal form of childcare for very young children. The Polish migrants appear to be immune to adoption of the Dutch way of childcare strategy when they have a child that is less than one year old. The strong influence of the home country is apparent also amongst parents of children who are one-year old children. However, in this age category the preferences of Polish migrants are much less clear-cut. The results revealed that the age of one is a critical age for the migrant parents in terms of childcare. We found that for children in this age category the Polish migrants prefer both sole parental care and institutional childcare. Upon further investigation, we found that this discrepancy is largely caused by the willingness of the Polish migrants to integrate within the Dutch society. We found that migrant parents who are more likely to participate in Dutch language courses, intend to settle in the Netherlands, have a Dutch partner, and are less likely to own a property in Poland are more likely to use institutional childcare with their one-year-old than their counterparts who have stronger bonds with Poland. The scepticism towards the institutional childcare seem to disappear when the child reaches the age of two. At that point the Polish parents in the Netherlands show clear preference for institutional childcare. However, our data do not allow to distinguish whether the strong preference for institutional childcare is driven by the absence of grandparental childcare or whether there is a strong preference for institutional childcare for children of this age category in the wider population of Polish parents. Despite that, our analyses provided an evidence of strong influence of home and host countries in the childcare strategies of Polish migrants in the Netherlands. 
Appendix. Logistic regression on use of sole parental care (Model 1) and on use of institutional childcare services (Model 2).

Model 1

Model 2

OR

Cl $95 \%$

OR

Cl $95 \%$

Age of the youngest child

0

1

2

3

Sample

Polish

Dutch

Migrants

Interaction terms

$1 *$ Migrants

$1 *$ Dutch

2*Migrants

$2 *$ Dutch

3*Migrants

3*Dutch

Demographics

Woman's age

Man's age

Woman's education

Low

Middle

High

Man's education

Low
1

$\begin{array}{lllllllll}0.7540 & & 0.5680 & 1.0009 & 1.2165 & & 0.8805 & 1.6806 \\ 0.5905 & * * * & 0.4392 & 0.7939 & 1.2757 & * & 0.9160 & 1.7768 \\ 0.4679 & * * * & 0.3346 & 0.6541 & 4.6609 & * * * & 3.3253 & 6.5329\end{array}$

1

$\begin{array}{llllllll}0.7270 & * * & 0.4355 & 1.2135 & 1.9083 & * * * & 1.0623 & 3.4279 \\ 0.0715 & & 0.0160 & 0.3184 & 4.4228 & * & 2.2453 & 8.7123\end{array}$

$\begin{array}{llllllll}0.8602 & & 0.4014 & 1.8436 & 1.3838 & & 0.6199 & 3.0893 \\ 0.7925 & & 0.1008 & 6.2282 & 1.0978 & & 0.4741 & 2.5418 \\ 0.4821 & & 0.1797 & 1.2936 & 3.4176 & * * & 1.3890 & 8.4086 \\ 4.0215 & & 0.7152 & 22.6126 & 0.8953 & * * & 0.3805 & 2.1068 \\ 0.3366 & * & 0.1172 & 0.9670 & 2.0844 & & 0.8348 & 5.2045 \\ 3.4053 & & 0.5727 & 20.2485 & 0.3559 & * & 0.1455 & 0.8704\end{array}$

$\begin{array}{lllllll}1.0393 & * & 1.0072 & 1.0723 & 0.9930 & 0.9625 & 1.0246 \\ 1.0070 & & 0.9820 & 1.0327 & 1.0065 & 0.9818 & 1.0319\end{array}$

$\begin{array}{llllllll}1.9850 & * * & 1.3331 & 2.9558 & 0.2909 & * * * & 0.1761 & 0.4803\end{array}$

11

$\begin{array}{llllllll}0.5034 & * * * & 0.3887 & 0.6519 & 1.6247 & * * * & 1.2704 & 2.0780\end{array}$

$\begin{array}{llllll}0.8805 & 0.6069 & 1.2774 & 0.7702 & 0.5226 & 1.1350\end{array}$ 


\begin{tabular}{|c|c|c|c|c|c|c|c|c|}
\hline Middle & 1 & & & & 1 & & & \\
\hline High & 0.8948 & & 0.6801 & 1.1773 & 1.6375 & $* * *$ & 1.2729 & 2.1066 \\
\hline $\begin{array}{l}\text { Number of children } \\
\text { household }\end{array}$ & 0.7109 & $* * *$ & 0.6280 & 0.8048 & 1.6746 & $* * *$ & 1.4849 & 1.8886 \\
\hline Woman is working & 0.2180 & $* * *$ & 0.1745 & 0.2722 & 2.5796 & $* * *$ & 2.0723 & 3.2112 \\
\hline Man is working & 0.6553 & $*$ & 0.4471 & 0.9603 & 0.9632 & & 0.6357 & 1.4594 \\
\hline Constant & 1.2751 & & 0.5929 & 2.7421 & 0.0467 & $* * *$ & 0.0204 & 0.1071 \\
\hline $\mathrm{N}$ & & & 2,286 & & & & 286 & \\
\hline
\end{tabular}

Notes: ${ }^{*} p \leq 5 \% ;{ }^{* *} p \leq 1 \% ;{ }^{* * *} p \leq 0.1 \%$ 


\section{References}

Aassve, A., Ajzen, I., Billari, F., Bühler, C., Dykstra, P., Fokkema, T., ... Thévenon, O. (2015).

Generations and Gender Survey Questionnaire, version 2.7. Retrieved from https://www.ggpi.org/wp-content/uploads/2017/08/GGS_Qre_Full_v2_7.pdf

Andringa, W., Nieuwenhuis, R., \& Van Gerven, M. (2015). Women's Working Hours: The Interplay between Gender Role Attitudes, Motherhood, and Public Childcare Support in 23 European Countries. International Journal of Sociology and Social Policy, 35(9/10), 582-599.

Belastingdienst. (2017). Berekening Kinderopvangtoeslag 2018. Retrieved from https://www.belastingdienst.nl/wps/wcm/connect/bldcontentnl/themaoverstijgend/brochures_en _publicaties/berekening-kinderopvangtoeslag-2018

Berkel, M. Van, \& Graaf, N. D. De. (1998). Married Women's Economic Dependency in the Netherlands, 1979-1991. The British Journal of Sociology, 49(1), 97-117.

Bjørnholt, M., \& Stefansen, K. (2018). Same but Different: Polish and Norwegian Parents' Workfamily Adaptations in Norway. Journal of European Social Policy.

Bojarczuk, S., \& Mühlau, P. (2017). Mobilising social network support for childcare: The case of Polish migrant mothers in Dublin. Social Networks, Online Fir.

Booth, A. L., \& van Ours, J. C. (2013). Part-time jobs: What women want? Journal of Population Economics, 26(1), 263-283.

Bussemaker, J. (1998). Rationales of Care in Contemporary Welfare States: The Case of Childcare in the Netherlands. Social Politics, 5(1), 70-96.

Cloïn, M., Keuzenkamp, S., \& Plantenga, J. (2011). A Matter of Culture and Cost? A Comparison of the Employment Decisions Made by Mothers With a Lower, Intermediate and Higher Level of Education in the Netherlands. Work, Employment and Society, 25(3), 468-486.

Da, W. W. (2003). Transnational Grandparenting: Child Care Arrangements Among Migrants from the People's Republic of China to Australia. Journal of International Migration and Integration/Revue de l'integration et de La Migration Internationale, 4(1), 79-103.

den Dulk, L. (2015). The Netherlands Country Note. In P. Moss (Ed.), International Review of Leave Policies and Research 2015.

Edlund, J., \& Öun, I. (2016). Who should work and who should care? Attitudes towards the desirable division of labour between mothers and fathers in five European countries. Acta Sociologica. http://doi.org/10.1177/0001699316631024

Eggeb $\varnothing$, H. (2010). The Problem of Dependency: Immigration, Gender, and the Welfare State. Social 
Politics, 17(3), 295-322.

ESS Round 5: European Social Survey Round 5 Data. (2010). Data File Edition 3.3. NSD -

Norwegian Centre for Research Data. Norway - Data Archive and Distributor of ESS Data for ESS ERIC.

Groenendijk, H., \& Keuzenkamp, S. (2011). The Netherlands Country Note. In P. Moss (Ed.), International Review of Leave Policies and Related Research 2011.

Hajdo, M. (2006). Wizerunek Kobiety Jako Matki, Pracownika i Działaczki Społecznej Prezentowany na Łamach Prasy Kobiecej w Latach 1948-1956. Dzieje Najnowsze, 38(3), 55-72.

Hartog, J., \& Theeuwes, J. (1993). Post-war Unemployment in the Netherlands. European Journal of Political Economy, 9(1), 73-112.

Heinen, J., \& Wator, M. (2006). Child Care in Poland Before, During, and After the Transition: Still a Women's Business. Social Politics, 13(2), 189-216.

Henkens, K., Meijer, L., \& Siegers, J. (1993). The Labour Supply of Married and Cohabiting Women in the Netherlands, 1981-1989. European Journal of Population, 9(4), 331-352.

Karpinska, K., Dykstra, P. A., \& Fokkema, T. (2016). Families of Poles in the Netherlands (FPN) Survey, Wave 1.

Keryk, M. (2010). 'Caregivers with a Heart Needed': The Domestic Care Regime in Poland after 1989 and Ukrainian Migrants. Social Policy \& Society, 9(3), 431-441.

Knijn, T., \& Saraceno, C. (2010). Changes in the Regulation of Responsibilities Towards Childcare Needs in Italy and the Netherlands: Different Timing, Increasingly Different Approaches. Journal of European Social Policy, 20(5), 444-455.

Koelet, S., Van Mol, C., \& De Valk, H. A. G. (2017). Social Embeddedness in a Harmonized Europe: the Social Networks of European Migrants with a Native Partner in Belgium and the Netherlands. Global Networks, 17(3), 441-459.

Kotowska, I. E. (1995). Discrimination against women in the labour market in Poland during the transition to a market economy. Social Politics, 2(1), 76-90.

Kotowska, I. E., \& Michon, P. (2011). Poland Country Note. In Peter Moss (Ed.), International Review of Leave Policies and Related Research 2011.

Kotowska, I., Jósźwiak, J., Matysiak, A., \& Baranowska, A. (2008). Poland: Fertility decline as a response to profound societal and labour market changes? Demographic Research, 19(December 2008), 795-854. http://doi.org/10.4054/DemRes.2008.19.22

Krapf, S. (2014). Who Uses Public Childcare for 2-year-old Children? Coherent Family Policies and 
Usage Patterns in Sweden, Finland and Western Germany. International Journal of Social Welfare, 23(1), 25-40.

Lewis, J., Knijn, T., \& Martin, C. (2008). Patterns of Development in Work/Family Reconciliation Policies for Parents in France, Germany, the Netherlands, and the UK in the 2000s. Social Politics, 15(3), 261-286.

Lister, R. (2009). A Nordic Nirvana? Gender, Citizenship, and Social Justice in the Nordic Welfare States. Social Politics, 16(2), 242-278.

Mamolo, M., Coppola, L., Di Cesare, M., Cesare, M. Di, Marija Mamolo, Lucia Coppola, ... Review. (2011). Formal Childcare Use and Household Socio-economic Profile in France, Italy, Spain and UK. Population Review, 50(1), 170-194.

Matysiak, A. (2009). Employment First, then Childbearing: Women's Strategy in Post-socialist Poland. Population Studies, 63(3), 253-76.

Mills, M., Praeg, P., Tsang, F., Begall, K., Derbyshire, J., Kohle, L., ... Hoorens, S. (2014). Use of Childcare Services in the EU Member States and Progress Towards the Barcelona Targets. Brussels. Retrieved from https://www.rand.org/pubs/research_reports/RR185.html

Nijhoff, K. G. (2017). Polish Migrants in The Hague: Stories of Integration and Attachment. Journal of International Migration and Integration, 18(2), 623-640.

Oyrzanowski, B., \& Paleczny-Zapp, M. (1993). From one economic ideology to another: Poland's transition from socialism to capitalism. International Journal of Politics, Culture and Society, 7(1), 43-55. http://doi.org/10.1007/BF02142346

Piętka-Nykaza, E., \& McGhee, D. (2017). EU Post-accession Polish Migrants Trajectories and Their Settlement Practices in Scotland. Journal of Ethnic and Migration Studies, 43(9), 1417-1433. http://doi.org/10.1080/1369183X.2016.1241137

Pott-Buter, H. A. (1993). Facts and Fairy Tales about Female Labor, Family and Fertility: A Sevencountry COmparison, 1850-1990. Amsterdam University Press.

Saraceno, C. (2011). Childcare Needs and Childcare Policies: A Multidimensional Issue. Current Sociology, 59(1), 78-96.

Saxonberg, S., \& Sirovátka, T. (2006). Failing Family Policy in Post-communist Central Europe. Journal of Comparative Policy Analysis: Research and Practice, 8(2), 185-202.

Saxonberg, S., \& Szelewa, D. (2007). The Continuing Legacy or the Communist Legacy? The development of family policies in Poland and the Czech Republic. Studies in Gender, State \& Society, 351-379. 
Share, M., Williams, C., \& Kerrins, L. (2017). Displaying and Performing: Polish Transnational Families in Ireland Skyping Grandparents in Poland. New Media \& Society, 146144481773927.

Siim, B. (2007). The Challenge of Recognizing Diversity from the Perspective of Gender Equality: Dilemmas in Danish Citizenship. Critical Review of International Social and Political Philosophy, 10(4), 491-511.

Sime, D., \& Pietka-Nykaza, E. (2015). Transnational Intergenerationalities: Cultural Learning in Polish Migrant Families and its Implications for Pedagogy. Language and Intercultural Communication, 15(2), 208-223.

Szelewa, D. (2012). Childcare Policies and Gender Relations in Eastern Europe: Hungary and Poland Compared, 1-28. Retrieved from http://www.harriet-taylor-mill.de/pdfs/discuss/DiscPap17.pdf Szelewa, D. (2017). From Implicit to Explicit Familialism: Post-1989 Family Policy Reforms in Poland. Gender and Family in European Economic Policy, 129-151. http://doi.org/10.1007/9783-319-41513-0

Turney, K., \& Kao, G. (2009). Pre-kindergarten Child Care and Behavioral Outcomes Among Children of Immigrants. Early Childhood Research Quarterly, 24(4), 432-444.

Wingens, M., Valk, H. de, Windzio, M., \& Aybek, C. (2011). The Sociological Life Course Approach and Research on Migration and Integration. In M. Wingens, M. Windzio, H. de Valk, \& C. Aybek (Eds.), A Life-Course Perspective on Migration and Integration (pp. 1-26). Springer. 